Bull. Mater. Sci., Vol. 36, No. 2, April 2013, pp. 245-249. (c) Indian Academy of Sciences.

\title{
Effect of curing time on microstructure and mechanical strength development of alkali activated binders based on vitreous calcium aluminosilicate (VCAS)
}

\author{
M M TASHIMA, L SORIANO, M V BORRACHERO, J MONZÓ and J PAYÁ* \\ Instituto de Ciencia y Tecnología del Hormigón, Universitat Politècnica de València, Camino de Vera s/n, Edificio 4G, \\ 46022 Valencia, Spain
}

MS received 30 January 2012; revised 10 May 2012

\begin{abstract}
The aim of this paper is to study the influence of curing time on the microstructure and mechanical strength development of alkali activated binders based on vitreous calcium aluminosilicate (VCAS). Mechanical strength of alkali activated mortars cured at $65^{\circ} \mathrm{C}$ was assessed for different curing times (4-168 h) using $10 \mathrm{molal}$ $\mathrm{NaOH}$ solution as alkaline activator. Compressive strength values around $77 \mathrm{MPa}$ after three days of curing at $65^{\circ} \mathrm{C}$ were obtained. 1.68 MPa/h compressive strength gain rate was observed in the first $12 \mathrm{~h}$, decreasing to $0.95 \mathrm{MPa} / \mathrm{h}$ for the period of 12-72 h. The progress of geopolymeric reaction was monitored by means of TGA and, electrical conductivity and $\mathrm{pH}$ measurements in an aqueous suspension. Significant decrease in $\mathrm{pH}$ and electrical conductivity were observed in the 4-72 h period, demonstrating the geopolymerization process. Furthermore, SEM images showed an important amount of (N, C)ASH gel and low porosity of the developed matrix.
\end{abstract}

Keywords. Compressive strength; alkali activation; vitreous calcium aluminosilicate; geopolymerization.

\section{Introduction}

The alkali activation process is a chemical reaction based on the polymerization of an alumino-silicate source material with a high alkaline solution to form stable binding material commonly called "alkali activated binder" or "geopolymer" (Duxson et al 2007; Davidovits 2008). This process involves the agglutination of small species (molecules and ions) in order to form larger ones that precipitate as a gel. This gel has generally been accepted as a zeolitic precursor (NASH gel), and it contains tetrahedral $\mathrm{SiO}_{4}$ and $\mathrm{AlO}_{4}$ randomly distributed along the polymeric chains which are cross-linked by oxygen bridges. The negative charge on the $\mathrm{AlO}_{4}^{-}$group is charge-balanced by alkali cations (typically $\mathrm{Na}^{+}$and/or $\mathrm{K}^{+}$) available in the alkaline solution (Fernández-Jiménez et al 2005; Duxson et al 2007; Yao et al 2009). As can be observed in the literature (Komnitsas and Zaharaki 2007; Pacheco-Torgal et al 2008a), the geopolymerization process depends essentially on three factors: alkaline solution, alumino-silicate source material and curing conditions. The most common alumino-silicate source materials used in the geopolymerization process are slags (Puertas et al 2000; Bernal et al 2011), metakaolin (Lin et al 2009; Marín-López et al 2009; Zivica et al 2011) and fly ashes (FernándezJiménez et al 2005; Lloyd et al 2009). However, in the last years, the use of different alumino-silicate materials have been performed: natural pozzolans (Xu and van Deventer

\footnotetext{
*Author for correspondence (jjpaya@ cst.upv.es)
}

2000; Najafi Kani et al 2012), tungsten mine waste (PachecoTorgal et al 2008b, c), ceramic waste (Puertas et al 2006; Reig et al 2010), FCC catalyst residue (Tashima et al 2012) construction and demolition waste (Lampris et al 2009; Payá et al 2012).

The alkaline solutions frequently used to produce geopolymers are sodium and/or potassium silicate solution due to the improvements in mechanical properties provided by the addition of extra soluble silica. Nevertheless, it is important to state that silicate solutions are expensive and its high cost may make unavailable the use of this component in alkaline activator. Some studies have been performed to substitute sodium silicate solution by silica fume (Zivica 2004) or nanosilica (Rodriguez et al 2012) dissolved in sodium hydroxide solution.

The other important factor that controls the geopolymerization process is the curing process. In this case, one must take into account of the following parameters: temperature, humidity and curing time. Most of the researches stated the importance of high relative humidity during the geopolymeric reaction due to the shrinkage problems that can be generated in dry curing conditions (Criado et al 2011). Concerning to the time and temperature of curing, it is important to point out that these variables are directly related between them: it means that for higher temperatures, less curing time is necessary to achieve the geopolymerization process.

In this paper, vitreous calcium aluminosilicate (VCAS) is used as alumino-silicate source material in the production of alkali activated binders. VCAS is a high reactive pozzolan which has been successfully used in blended Portland cement 
(Hossain et al 2008; Neithalath et al 2009). The first study related to the application of VCAS in alkali-activated systems was performed by Tashima et al (2009). The authors studied the influence of $\mathrm{NaOH}$ concentration for alkali activated mortars cured at $65^{\circ} \mathrm{C}$ for three days: the obtained mortars showed important enhancement in compressive strength, especially for alkaline solutions with 10 molal in $\mathrm{NaOH}$.

In this paper, a specific study is carried out on the influence of curing time on the development of mechanical strength of alkali activated VCAS (AA-VCAS) mortars activated by 10 molal $\mathrm{NaOH}$ solution.

\section{Experimental}

The vitreous calcium aluminosilicate (VCAS), supplied by Vitrominerals, was used as alumino-silicate source material in the production of alkali-activated binders. Its chemical composition, determined by XRF, is shown in table 1 . This material presents a mean particle size of about $12 \mu \mathrm{m}$ and irregular shape morphology with a dense-compact structure (see figure 1). In figure 2, the XRD pattern for VCAS sample is presented. The XRD pattern indicates that VCAS is an amorphous material which was identified by the baseline deviation in the range of $15-35^{\circ}$. The presence of quartz crystals as impurities is detected by its characteristic pattern: quartz (PDFCARD-461045).

A 10 molal alkaline solution was prepared using sodium hydroxide (98\% purity) supplied by Panreac SA. The mortar

Table 1. Chemical composition of VCAS (wt \%).

\begin{tabular}{cccccccc}
\hline $\mathrm{SiO}_{2}$ & $\mathrm{Al}_{2} \mathrm{O}_{3}$ & $\mathrm{CaO}$ & $\mathrm{MgO}$ & $\mathrm{Na}_{2} \mathrm{O}$ & $\mathrm{K}_{2} \mathrm{O}$ & $\mathrm{Fe}_{2} \mathrm{O}_{3}$ & Others \\
\hline 57.9 & 12.92 & 23.51 & 2.88 & 0.74 & 0.13 & 0.47 & 1.45 \\
\hline
\end{tabular}

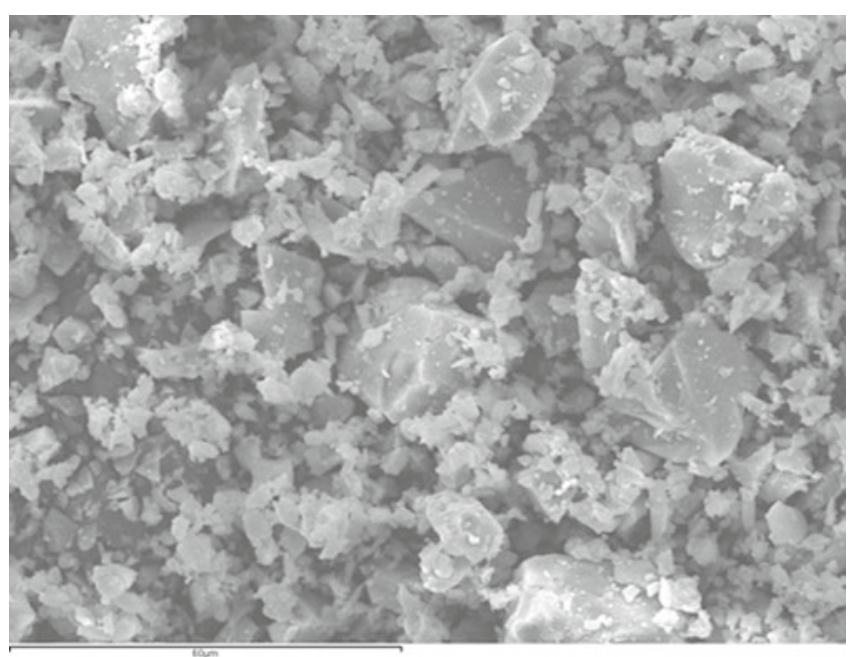

Figure 1. SEM image of VCAS sample.

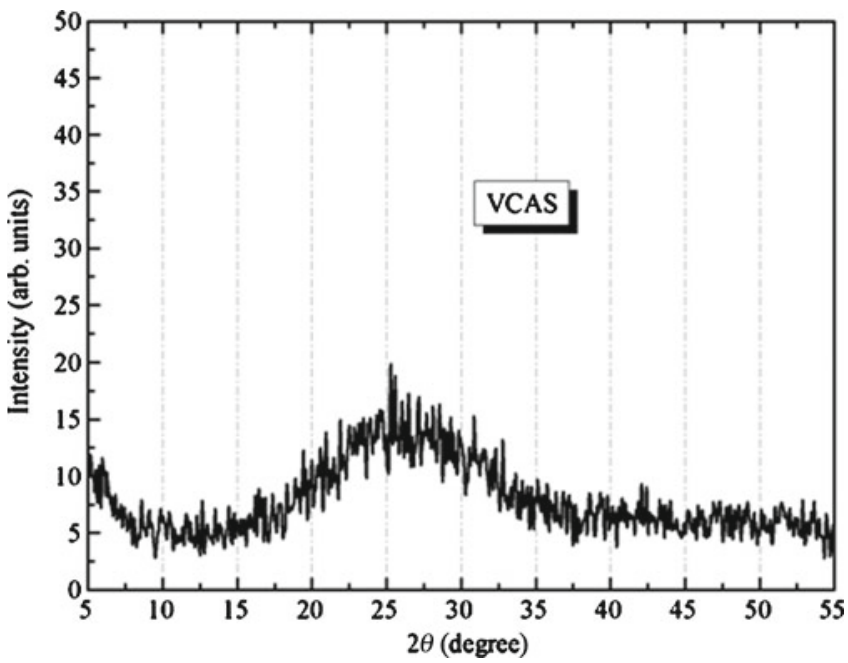

Figure 2. XRD pattern for VCAS sample.

samples (AA-VCAS mortars) were prepared using siliceous sand (UNE-EN 196-1 standard). The sand/VCAS ratio was fixed to 3 and the water/VCAS ratio was 0.45 . The mortar specimens $\left(40 \times 40 \times 160 \mathrm{~mm}^{3}\right)$ were cured at $65{ }^{\circ} \mathrm{C}$ in high relative humidity ( $\mathrm{RH} \sim 100 \%$ ) for different curing times: 4, 8, 12, 24, 48, 72 and $168 \mathrm{~h}$. Mechanical strength tests were performed in an universal test machine following the procedures described on UNE-EN 196-1 standard. Flexural strength is an average calculated from three samples and the compressive strength is an average calculated from six samples (standard deviation values were also calculated).

Similar mixtures without sand (pastes) were prepared for the microstructural analysis. The geopolymerization process of AA-VCAS pastes was monitored by means of electrical conductivity and $\mathrm{pH}$ measurements in an aqueous suspension. In this case, a Crison microCM2201 conductimeter and a Crison micropH2001 pH-meter (Alkali resistant pH-electrode Crison 5204) were used. This analysis was performed using $1 \mathrm{~g}$ of milled alkali-activated VCAS paste and $10 \mathrm{ml}$ of deionized water. The mixture was magnetically stirred for $10 \mathrm{~min}$ before the conductivity and $\mathrm{pH}$ measurements. Thermogravimetric analysis (TGA) characterization of AA-VCAS pastes were carried out in a TGA 850 Mettler Toledo thermobalance, using sealed and pin-holed $100 \mu \mathrm{L}$-aluminum crucibles in a nitrogen atmosphere in the $35-600{ }^{\circ} \mathrm{C}$ range at $10{ }^{\circ} \mathrm{C} / \mathrm{min}$ heating rate. Pastes studied by TGA were previously ground with acetone and filtered under vacuum, and then dried at $60{ }^{\circ} \mathrm{C}$ for $30 \mathrm{~min}$. Scanning electron microscopy (SEM) JEOL JSM-6300 was used to analyse the microstructure development of fractured surface pastes.

\section{Results and discussion}

\subsection{Mechanical strength studies}

Table 2 summarizes the mechanical strength values of AA-VCAS mortars cured at $65^{\circ} \mathrm{C}$ for different times in 
$4-168 \mathrm{~h}$ range. A continuous increase in the mechanical properties (flexural $R_{\mathrm{f}}$ and compressive $R_{\mathrm{c}}$ strengths) of AAVCAS mortars are observed with the curing time. Flexural strength values higher than $7 \mathrm{MPa}$ were obtained after $48 \mathrm{~h}$ of thermal treatment. After this curing age, the flexural strength was maintained in similar values. The maximum flexural strength obtained for AA-VCAS mortars was similar to those obtained for standard mortars using ordinary Portland cement. No evidence of flexural decay were identified, confirming the stability of the binding matrix in these curing conditions.

The increase in compressive strength was also observed with the curing time. In figure 3 , the effect of curing time on the compressive strength development of alkali-activated VCAS mortars activated with 10.0 molal of $\mathrm{NaOH}$ is shown. Mortars cured for few hours present an acceptable compressive strength, achieving 5.6 MPa in $4 \mathrm{~h}$. As can be observed, an interesting compressive strength development is observed for this system in the first $72 \mathrm{~h}$ : a compressive strength gain rate around $1.68 \mathrm{MPa} / \mathrm{h}$ was observed for AA-VCAS mortars in the first $12 \mathrm{~h}$, decreasing to $0.95 \mathrm{MPa} / \mathrm{h}$ for a period of

Table 2. Influence of curing time on the mechanical properties of AA-VCAS mortars.

\begin{tabular}{llr}
\hline & $R_{\mathrm{f}}(\mathrm{MPA})$ & \multicolumn{1}{c}{$R_{\mathrm{c}}(\mathrm{MPA})$} \\
\hline $4 \mathrm{~h}$ & $0 \cdot 87 \pm 0 \cdot 20$ & $5.60 \pm 0.44$ \\
$8 \mathrm{~h}$ & $2 \cdot 19 \pm 0 \cdot 16$ & $13.63 \pm 0.61$ \\
$12 \mathrm{~h}$ & $2 \cdot 52 \pm 0 \cdot 03$ & $20.21 \pm 1 \cdot 11$ \\
$24 \mathrm{~h}$ & $3.99 \pm 0.46$ & $34.73 \pm 1.69$ \\
$48 \mathrm{~h}$ & $7.68 \pm 0 \cdot 87$ & $55 \cdot 23 \pm 1.90$ \\
$72 \mathrm{~h}$ & $7.61 \pm 0.46$ & $77.18 \pm 2 \cdot 25$ \\
$168 \mathrm{~h}$ & $7.94 \pm 0.32$ & $79.83 \pm 2.05$ \\
\hline
\end{tabular}

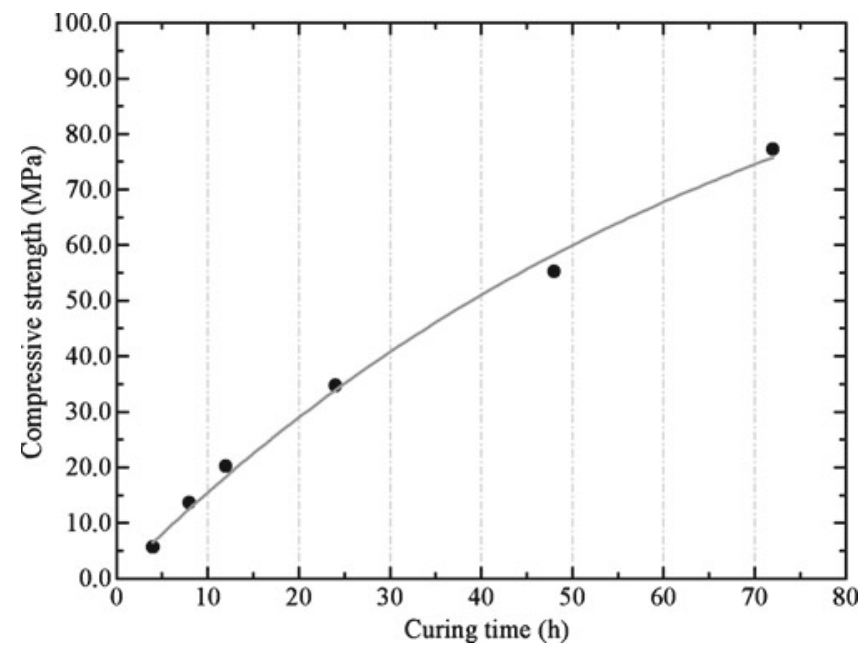

Figure 3. Compressive strength development of AA-VCAS mortars. Solid circles are experimental data and solid line is fitting curve according to (1).
$12-72 \mathrm{~h}$. After $72 \mathrm{~h}$ of curing, the increase in the compressive strength is negligible (see table 2).

The compressive strength results suggest that AA-VCAS mortars activated with $10 \cdot 0$ molal $\mathrm{NaOH}$ solution and cured with $\sim 100 \% \mathrm{RH}$ at $65^{\circ} \mathrm{C}$ temperature should be cured for 3 days ( $72 \mathrm{~h}$ ) to achieve very good compressive strength. An increase in the curing time for $168 \mathrm{~h}$ does not present a significant increment on the mechanical properties of AA-VCAS mortars. The curve of compressive strength $\left(R_{\mathrm{c}}\right)$ vs curing time ( $t, \mathrm{~h}$, range 4-72 h) for AA-VCAS mortar can be fitted $\left(R^{2}=0.99\right)$ using the following mathematical model:

$$
R_{\mathrm{c}}=a *\left(1-b^{t}\right)
$$

where $R_{\mathrm{c}}$ is the compressive strength (MPa); $t$ the curing time (h); $a$ and $b$ are 120.45 and $0.9863(\mathrm{MPa})$, respectively.

\subsection{Microstructural studies}

Thermogravimetric analyses (TGA) of AA-VCAS pastes for different curing times are summarized in table 3 . The results showed an increase in the total weight loss (\%) with the curing time. After $72 \mathrm{~h}$ of curing, the total weight loss achieves a maximum value of $19.17 \%$. The increase in weight loss is related to the progress of geopolymerization process. The dissolution process in alkaline medium implies that $\mathrm{Si}-\mathrm{O}-$ $\mathrm{Si}, \mathrm{Al}-\mathrm{O}-\mathrm{Al}$ and $\mathrm{Si}-\mathrm{O}-\mathrm{Al}$ bonds are broken, yielding $\mathrm{Al}-$ $\mathrm{OH}$ and $\mathrm{Si}-\mathrm{OH}$ groups. In the geopolymerization process, part of these new groups are arranged (condensation reaction) to form new $\mathrm{Si}-\mathrm{O}-\mathrm{Al}$ bonds. However, some of the $\mathrm{Si}-$ $\mathrm{OH}$ and $\mathrm{Al}-\mathrm{OH}$ groups remain unreacted. The weight loss observed in TGA for geopolymerized paste is attributed to the decomposition (water loss) of these $\mathrm{Si}-\mathrm{OH}$ groups and $\mathrm{Al}-\mathrm{OH}$ groups, and also to the water molecules bonded to ions (sodium and calcium).

Another instrumental technique used to assess the geopolymerization reaction is the analysis of $\mathrm{pH}$ and electrical conductivity measurements of geopolymeric pastes in an aqueous suspension. For this purpose, water suspensions $(1 \mathrm{~g}$ of milled geopolymerized paste and $10 \mathrm{~g}$ of deionized water) were prepared for each curing time: in these conditions, free $\mathrm{OH}^{-}$and $\mathrm{Na}^{+}$ions were released from the pores of the powdered paste to the solution. The results showed a decrease in the $\mathrm{pH}$ and the electrical conductivity values, indicating the geopolymerization reaction progress by the consumption of $\mathrm{OH}^{-}$and $\mathrm{Na}^{+}$ions. Figure 4 shows the $\mathrm{pH}$ and electrical conductivity changes for different curing times. In the first $48 \mathrm{~h}$ of the reaction, a decrease in the $\mathrm{pH}$ values is detected, from 13.35 to $12 \cdot 59$. Similar results are presented by electrical

Table 3. Total weight loss (\%) for AA-VCAS pastes at different curing times.

\begin{tabular}{lcccccc}
\hline Curing time (h) & 3 & 12 & 24 & 48 & 72 & 168 \\
AA-VCAS & 7.71 & 11.09 & 13.42 & 15.79 & 19.17 & 18.06 \\
\hline
\end{tabular}


conductivity measurements: a decrease from $42800 \mu \mathrm{S} / \mathrm{cm}$ to $9430 \mu \mathrm{S} / \mathrm{cm}$.

After $48 \mathrm{~h}$ of curing, no changes are observed in $\mathrm{pH}$ and electrical conductivity values. Nevertheless, comparing these results with mechanical properties of mortars, it can be assumed that the improvement on compressive strength is related to the reorganization in the microstructure of AA-VCAS system. The microstructure development of

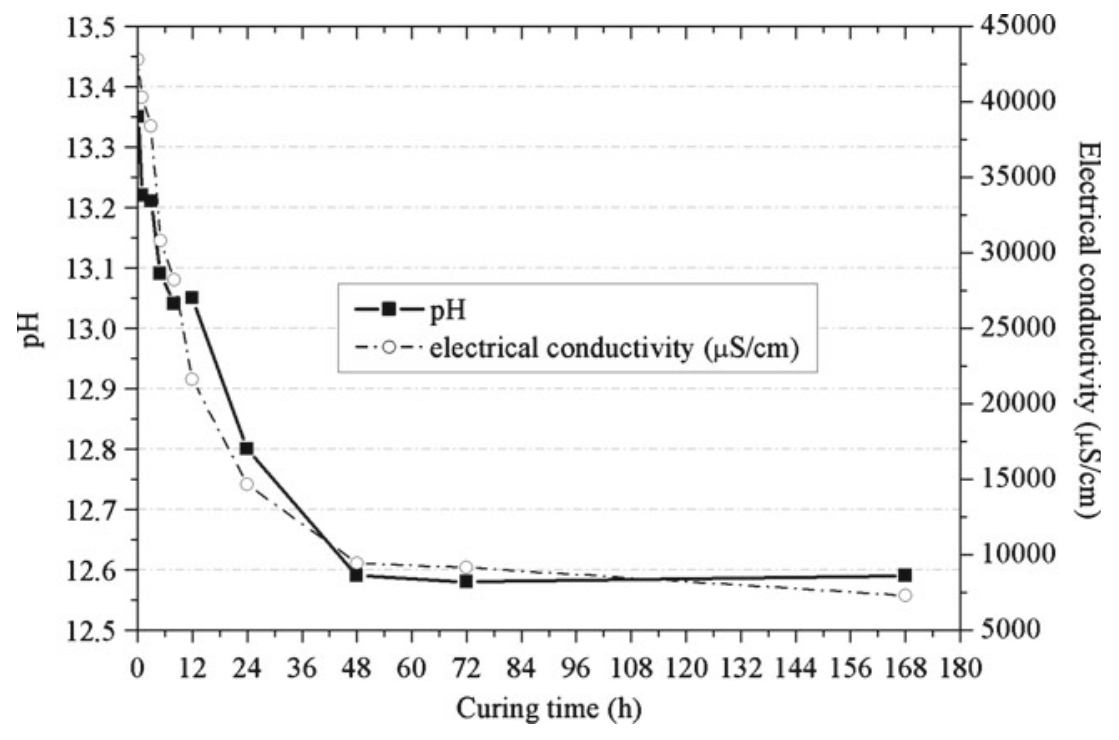

Figure 4. $\mathrm{pH}$ and electrical conductivity values for AA-VCAS pastes for different curing times.
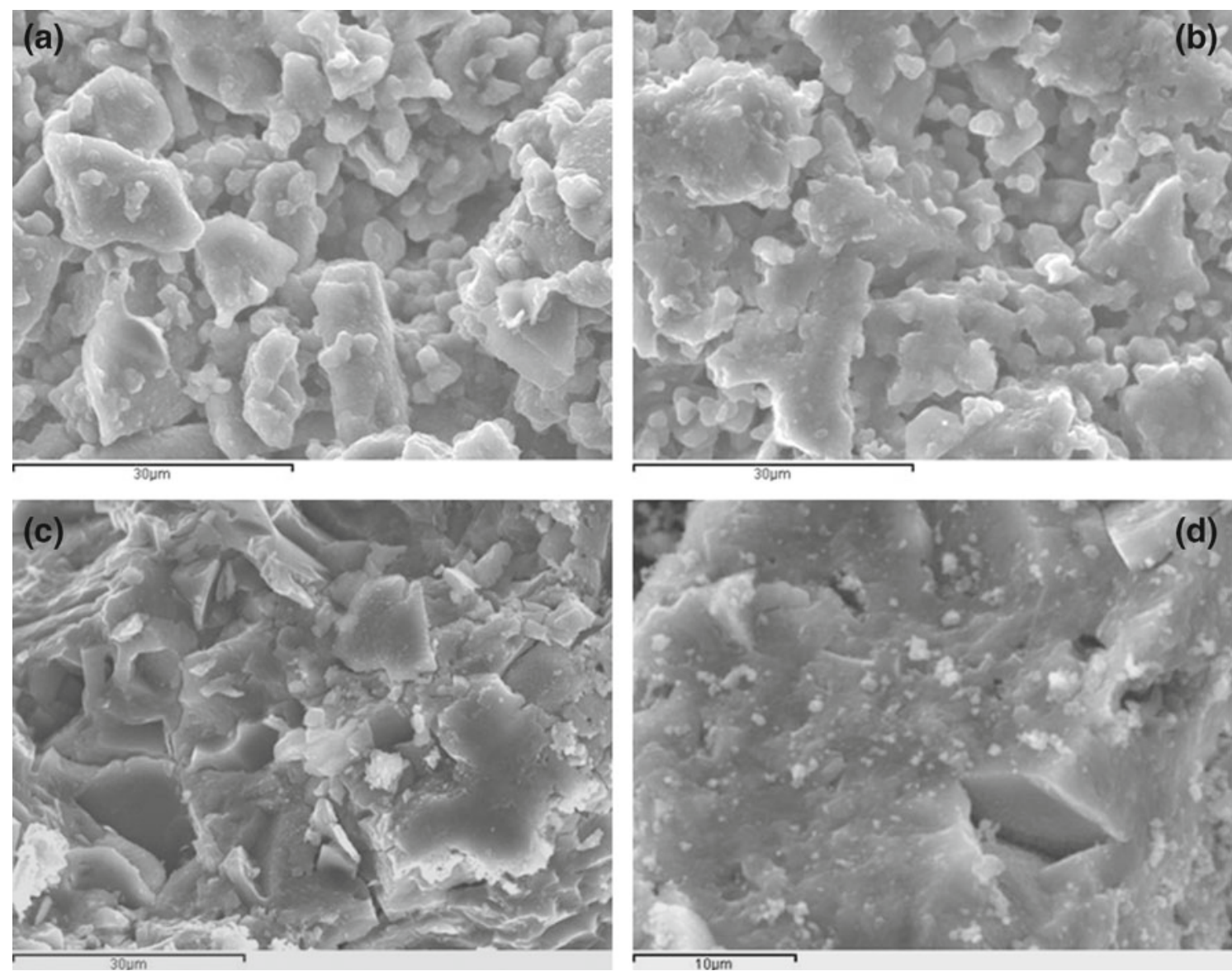

Figure 5. SEM images of AA-VCAS paste for different curing times: (a) $1 \mathrm{~h}$; (b) $4 \mathrm{~h}$; (c) and (d) $72 \mathrm{~h}$. 
AA-VCAS pastes were also analysed by means of SEM images for different curing times. In the first hour, the dissolution-coagulation process of alumino-silicate source material can be identified. In figure 5(a), a SEM image of AA-VCAS paste cured for $1 \mathrm{~h}$ at $65^{\circ} \mathrm{C}$ is shown. It can be noticed that some VCAS particles have been dissolved and small amount of gel was formed. When the curing time was increased to $4 \mathrm{~h}$, the formation of an amorphous gel (characterized by EDX as (N,C)ASH gel) can be identified (see figure 5(b)). For this curing time, the AA-VCAS paste also presents a very porous microstructure.

Pastes cured for 3 days at $65{ }^{\circ} \mathrm{C}$ (figures $5 \mathrm{c}$ and $\mathrm{d}$ ), a compact-dense microstructure is observed. In this case, the presence of partially reacted VCAS particles can also be noted (see figure 5(d), up-right corner), and the amount of amorphous gel is very high, occupying an important part of the volume in the sample.

\section{Conclusions}

The effect of curing time on the microstructure and mechanical strength development of alkali activated VCAS have been investigated. High compressive strength mortars are obtained, yielding an important increase to $77 \mathrm{MPa}$ for 3 days of curing at $65^{\circ} \mathrm{C}$. A mathematical model of compressive strength development of AA-VCAS mortars was proposed in the range 4-72 h. Electrical conductivity and $\mathrm{pH}$ measurements suggested that $48 \mathrm{~h}$ curing at $65^{\circ} \mathrm{C}$ led to an increase in the geopolymerization process. A decrease of free $\mathrm{OH}^{-}$ and $\mathrm{Na}^{+}$ions in the pore solution was related to the reaction progress. AA-VCAS pastes activated with 10 molal of $\mathrm{NaOH}$ after $72 \mathrm{~h}$ of reaction presented large amount of amorphous $(\mathrm{N}, \mathrm{C}) \mathrm{ASH}$ gel.

\section{Acknowledgements}

To the Ministerio de Ciencia e Innovación (MICINN) of the Spanish Government (BIA2011-26947) and also to FEDER for funding and to Vitrominerals company for supplying VCAS samples.

\section{References}

Bernal S A, Gutiérrez R M, Pedraza A L, Provis J L, Rodriguez E D and Delvasto S 2011 Cem. Concr. Res. 411
Criado M, Fernández-Jiménez A, Sobrados I, Palomo A and Sanz J 2011 J. Eur. Ceram. Soc. avaiable online

Davidovits J 2008 Geopolymer chemistry and applications Institute Geopolymere, Saint-Quentin, France

Duxson P, Fernández-Jiménez A, Provis J L, Lukey G C, Palomo A and van Deventer J S J 2007 J. Mater. Sci. 472917

Fernández-Jiménez A, Palomo A and Criado M 2005 Cem. Concr. Res. 351204

Hossain A B, Shrazi S A, Persun J and Neithalath N 2008 J. Transp. Res. Board 207032

Komnitsas K and Zaharaki D 2007 Miner. Eng. 201261

Lampris C, Lupo R and Cheeseman C R 2009 Waste Manage. 29 368

Lin T, Jia D, Wang M, He P and Liang D 2009 Bull. Mater. Sci. 32 77

Lloyd R R, Provis J L and van Deventer J S J 2009 J. Mater. Sci. 44 608

Marín-López C, Reyes Araiza J L, Manzano-Ramírez A, Rubio Avalos J C, Perez-Bueno J J, Muñiz-Villareal M S, VenturaRamos E and Vorobiev Y 2009 Inorg. Mater. 451429

Najafi Kani E, Allahverdi A and Provis J L 2012 Cem. Concr. Comp. 3425

Neithalath N, Persun J and Hossain A 2009 Cem. Concr. Res. 39 473

Pacheco-Torgal F, Castro-Gomes J and Jalali S 2008a Constr. Build. Mater. 221315

Pacheco-Torgal F, Castro-Gomex J and Jalali S 2008b Constr. Build. Mater. 221201

Pacheco-Torgal F, Castro-Gomex J and Jalali S 2008c Constr. Build. Mater. 222212

Payá J, Borrachero M V, Monzó J, Soriano L and Tashima M M 2012 Mater. Lett. 74223

Puertas F, Martínez-Ramírez S, Alonso S and Vázquez T 2000 Cem. Concr. Res. 301625

Puertas F, Barba A, Gazulla M F, Gómez M P, Palacios M and Martínez-Ramírez S 2006 Mater. Construc. 5673

Reig L, Tashima M M, Borrachero M V, Monzó J and Payá J 2010 II Simposio aprovechamiento de residuos agro-industriales como fuente sostenible de materiales de construcción $\mathrm{p} .83$

Rodriguez E D, Bernal S A, Provis J, Payá J, Monzó J and Borrachero M V 2012 Cem. Concr. Comp. (submitted)

Tashima M M, Borrachero M V, Monzó J, Soriano L and Payá J 2009 COMATCOMP09 p.421

Tashima M M, Akasaki J L, Castaldelli V N, Soriano L, Monzó J, Payá J and Borrachero M V 2012 Mater. Lett. 8050

Xu H and van Deventer J S J 2000 Int. J. Miner. Process. 59247

Yao X, Zhang Z, Zhu H and Chen Y 2009 Thermochim. Acta 49349

Zivica V 2004 Bull. Mater. Sci. 27179

Zivica V, Balkovic S and Drabik M 2011 Constr. Build. Mater. 25 2206 